\title{
Exploring the Concept of Teaching Faculty Motivation
}

\author{
Valerie Mannix \\ Waterford Instiutute of Technology, Ireland
}

\begin{abstract}
This discussion paper explores the concept of teaching faculty motivation. The writing of this paper emanates from findings of a qualitative/quantitative PHD study, which explored the motivation of both language learners and language teaching faculty at Waterford Institute of Technology, Ireland.

In light of these findings pertaining to teaching faculty motivation and in view of more recent calls for the enhancement of educational faculty development and the quality of education provision, this discussion paper seeks to provide thereafter an analysis of the characteristics of the motivation to teach. Consideration is also given to the context of profound changes globally, socially and economically being witnessed and experienced by teaching faculty today.

In conclusion, the paper makes a number of recommendations geared towards best practice pertaining to teaching faculty motivation. Of crucial importance, it is advocated, is the promotion of the concept of possible and ideal selves in the profession as well as the promotion of reflective spaces and possibilities for alternative contingency paths.
\end{abstract}

\section{Introduction}

This decade has seen profound changes in education, globally, socially and economically. As a result Governments throughout the world are shaping their educational policies constantly. Writing more than a decade ago, Altbach [1, p.14], in fact asserted that facing fiscal restraints, increased student enrolments and accountability were becoming increasingly part of the vocabulary of academic life. It would seem that despite efforts on behalf of faculty worldwide to re-vision, recreate and rethink the way academic teaching units function and the way curricula is delivered in order to accommodate such changes, a great deal remains to be accomplished. In particular, the question of the promotion of educational faculty development and faculty motivation needs to be at the forefront of discussions concerned with the quality of education provision.

It could be argued that although educational management is multi-dimensional, all organizational activities are, nevertheless centered around the performance of staff, which is correlated to staff motivation.

From a review of the literature on faculty motivation, it would also seem that teaching faculty and non-teaching faculty are witnessing worldwide an erosion of a sense of community amongst themselves due to changing patterns of enrolments and academic hiring.

More than a decade ago, Altbach [1], also highlighted the most important development in Europe as being the diversification of the types of appointments made to teaching and research posts. $\mathrm{He}$ further highlighted the fact that "the greatest impact on the profession would be an increase in the proportion of academic staff without permanent positions and the greater use of part-time lecturers [1, p.14]. This trend has been most prevalent in the United States over the past number of decades [11].

The change in recruitment patterns in Universities and Institutes of Technology in recent years in Ireland has become a major concern and because of it is recent nature; it is not yet possible to quantify the extent of its occurrence.

In line with widespread calls for the enhancement of educational faculty development and the quality of education provision in such changing and challenging times, this discussion paper aims to create further awareness of the importance of teaching faculty motivation in higher education. It places a strong emphasis, in particular, for the need to encourage teaching faculty to continuously pursue the notion of possible and ideal selves as well as the notion of identity play in work environments. It is argued that too often the notion of identity work amongst teaching faculty is perceived as the best possible avenue towards the enhancement of educational faculty development.

The paper focuses firstly on a qualitative/quantative research study, which explored the motivation of language teaching faculty at Waterford Institute of Technology, Ireland. This study has led to a further exploration of the concept of teaching faculty motivation and the writing of the paper.

Thereafter the paper focuses on conceptualizing "the motivation to teach" in higher education. There is a particular focus in this paper on the inherent intrinsic nature of the motivation of beginning and existing teaching faculty to remain in the profession. This paper additionally discusses the temporal dimension of teaching faculty motivation, that is, the notion of teaching as a life-long career.

The impact of micro- and macro-contextual variables pertaining to higher education on teacher faculty motivation is also examined.

The paper highlights, in particular, the importance of the promotion of open contingency 
paths as part of ongoing professional development for both part-time and full-time teaching faculty in higher education. Very much associated with this notion is the promotion of possible and ideal selves, self-authorisation, self-reflection critical engagement in multiple spaces as well the concept of identity play. In conclusion, the paper makes a number of recommendations geared towards best practice pertaining to teaching faculty motivation as well as the overall enhancement of educational faculty development.

\section{Study on faculty motivation at Waterford IT}

As motivation is in general a multifaceted concept, the study conducted at Waterford Institute of Technology on language teaching faculty was predominantly qualitative in nature. Quantification of data was employed in order to deduce patterns or trends in relation to the most predominant factors, which impacted teaching faculty motivation. The size of the sample of 18 participants was too small, however, for statistical analysis to be carried out successfully.

The following research methods were utilised: diaries of teachers, semi-structured interviews, openended questionnaires and motivation sheets completed by participants. The rationale behind the employment of various research methods was to complement and to corroborate the various sources of data and for comparative reasons.

Although there was a gender imbalance among the eighteen participants ( 3 males, 15 females), a diverse population was represented in the study in terms of age, qualification, level of experience and teaching contract. Regarding qualifications, all of the lecturers had both a undergraduate degree and postgraduate degree, that is, a masters qualification. Five lecturers had an additional teaching qualification. Only a small proportion of lecturers had doctoral degrees.

Both part-time and full-time teaching faculty were represented in the study. The overall majority of the teaching faculty participants had been teaching languages at WIT for five years of more.

In the study, it emerged overall from the elicited data from each research instrument that the most important factor impacting the motivation and demotivation of language teaching faculty was the student-teacher relationship. The perceptions of teaching faculty regarding the impact of the quality of their teaching on student motivational orientations was also significant, as illustrated in Table 1. In addition, it emerged that teaching faculty entered the profession primarily due to the love of their subject discipline and their sense of vocation.
Table 1. Perceptions of teaching faculty regarding the impact of the quality of their teaching and student motivational orientations on their motivation to teach

\begin{tabular}{|c|}
\hline Students who are interested $16.66 \%$ \\
\hline Student progress $16.66 \%$ \\
\hline Being in control of my work $14.29 \%$ \\
\hline Familiarity with course material $11.9 \%$ \\
\hline Familiarity with students $11.9 \%$ \\
\hline Topics which are interesting to teach $11.9 \%$ \\
\hline Other $16.66 \%$ \\
\hline
\end{tabular}

For some teaching faculty being "in control of their work" and been familiar with course material seemed to more important in regard to their perceptions of being effective practitioners $(25 \%$ of the overall motivating factors) rather than teaching topics which were of interest to them $(11.9 \%$ of the overall motivating factors).

Lecturers also highlighted the relevance of their motivational role in promoting and enhancing learner's goal-orientatedness. They documented as a source of self-motivation their role in helping learners to work towards their goals and to visualize what they would like to achieve for themselves.

With respect to the factors that contribute to teacher demotivation, the most significant factor was again the student, amounting to $33.32 \%$ of the overall factors recorded. Such students were documented as those who were unwilling to participate or did not attend regularly $(14.5 \%$ of the overall demotivating factors recorded). Lecturer 2 described such students in the following way in her diary:

"students who exploit me/others in the class - the ones that are never there and then demand that special concessions be made for them".

Associated with this factor was a lack of student progress (accounting for $13.04 \%$ of the overall findings), described by Lecturer 3 as "soul destroying". Furthermore, at the group interview, language lecturers spoke of the different orientations or lack of orientations of students. Some language learners were perceived as "aimlessly motivated", that is, a student who is not focused on a specific goal. In some instances, there also appeared to be a fear around working with particular students.

"There are actually students, whom I am afraid of. I go in hoping they are not there, because I'm afraid they are going to stare at me and make me 
feel embarrassed. I become completely panicked for the hour". (Lecturer 7).

The second most significant motivating factor which, emerged were lecturers' perceptions of the promotion of their sense of autonomy in regard to teaching and research. It was documented that finding sufficient time to be autonomous (for example, development of personal research interests, which also related to their teaching) was difficult. Teaching faculty autonomy was negatively impacted by an increasing workload (third most significant demotivating factor recorded) and a lack of sufficient support from superiors as well as a lack of training opportunities.

Collegial support played a significant role with respect to the motivation levels of language teaching faculty. To quote one example:

"I get motivated by support from colleagues and I like to have the opportunity to meet other people. It is actually quite different, if you go through a whole day with five hours of teaching and you have seen nobody other than your students". (Lecturer 4, extracted from diary).

Teaching participants also identified a number of factors, which impacted their overall motivation to teach. These included management and superiors (34.5\% of the demotivating factors), general facilities and learning facilities $(27.6 \%$ overall demotivating factors), course related factors $(13.7 \%$ of overall demotivating ) and lastly colleagues $(6.9 \%$ of overall demotivating factors).

\section{Toward a conceptualisation of the motivation to teach in Higher Education}

To date, there have been a number of studies on faculty motivation at University level, [for an extensive overview, see 13]. Some studies have focused on successful and unsuccessful faculty members [for an extensive overview, see 13]. Others have focused on the role of a supportive teaching culture in regard to faculty motivation [for an extensive overview, see 13]. There have also been some studies focusing on motivating teaching staff in times of change in Universities (for example, Hongping [24]). Other studies also focus on the impact of the student-teacher relationship on teaching faculty motivation and on the relationship between perceived quality of teaching and students' motivational orientations in a higher education context, for example [13] and [3].

There are, however, few publications discussing the precise nature of the "motivation to teach". Research in this area in the field of education has been largely fragmentary.
The work of Dörnyei [5] in the field of second acquisition on defining the "motivation of teach" as well as the work of Magdalena Kubanyiova [12] on possible selves and language teacher development has been of particular importance for this paper. Much of this work, it could also be deemed to be of particular relevance for researchers in the field of education.

Although teaching faculty show considerable variations across geographical locations, subject matters and the level of education they work at, there appears to be certain commonalties regarding "the motivation to teach" which are sufficiently robust to allow for some generalizations [13].

Furthermore, in a chapter entitled, "Teacher Motivation", Dörnyei [5], for example, claims that with such a specific professional activity as teaching, it might be realistic "to expect to find certain unique motivational characteristics", that is, "to identify some factors that have a special significance in terms of their impact on the motivation complex underlying teaching" [5, p.157]. Dörnyei further goes on to suggest four motivational aspects which seem to be particularly relevant with respect to teacher motivation and which could be applied to a higher education context.

Teacher motivation, according to Dörnyei [5, p.157] involves, firstly, a prominent intrinsic component as a main constituent. In other words it could be argued that teaching faculty, for the purposes of this paper, are motivated to enter higher education for the love of one's discipline and the vocational aspect of imparting and sharing knowledge for the betterment of all.

Secondly it is closely associated with institutional demands and constraints of the workplace, and the social profile of the profession.

Taking this point into consideration, it could be argued from a higher education perspective that both mico- and macro sociocontextual variables have both a positive and negative impact on the motivation of teaching faculty in higher education.

At mico-level it may include, for example, the enhancement or erosion of communities of practice, increasing workloads or multi-level management styles or hiring practices. Examples of this at macro level may include education policy at governmental level or public perceptions concerning higher education provision.

Thirdly Dörnyei [5, p.157] highlights that the "motivation to teach" concerns, along with all the other types of career motivation, an extended, lifelong process. Thus, it could be argued that in the context of higher education that the motivation of teaching faculty in higher education will fluctuate as teaching faculty progress through the various stages of the academic teaching career. Recent recruitment practices may also impact this development along an extended lifelong process. 
Fourthly, Dörnyei [5] advocates that the concept of "teacher motivation" appears in general to be exposed to several powerful negative influences, some being inherent in the wider teaching profession such as the stressful nature of the teaching profession and the erosion of both teacher and teaching efficacy.

\section{Teaching as an intrinsically motivated behavior}

It could be argued that the intrinsic teaching faculty motivation is very much linked to the futureorientated theory and notion of possible and ideal selves (discussed below) and Colin Riches [18, p.24] assertion that motivation refers to "individual differences with regard to the priorities, attitudes and aspects of lifestyle that individuals seek to fulfil in a work context" and the argument placed by Ibarra and Petriglieri [10] on the need for a more enhanced cultivation both the notion of identity work and identity play (discussed further below).

In conceptualising firstly motivational self-states, it is important to present how influential theorists perceive the notion of 'self' and how they distinguish between facets of 'self'

MacIntyre et al. [12] have indeed highlighted that the notion of 'self' is "one of the most frequently and most diversely used concepts in Psychology" (pg. 43). Indeed Higgins [8, p. 319- 320] also highlights that over a number of decades "different facets of the 'self' or self-images have been identified. He provides a number of examples including the work of James (1890/1948) on 'spiritual and social selves'; Rogers (1961) distinction between the normative standard 'what a person should and ought to be' and 'what he or she would ideally like to be'; and Colby's distinction between 'wish beliefs' (what one would like to do) and 'value-beliefs' (what one ought to do).

Traditionally there has a predominant focus on the static notion of the 'actual self' - defined as the kind of person an individual believes he or she is and the kind of person an individual believes that others think he/she actually is [8, p. 319]. More recently, however, self-theorists have become increasingly pre-occupied with the active dynamic nature of the self-system.

It is perceived in this paper that the self-system, which most influences our behaviour as teaching faculty in response to our perceptions and experiences are future self-representations known as 'possible selves'. This view is very much in line with the view of Ibarra and Petriglieri [10, p. 11] who advocate that members of organizations need to engage in "provisional but active trail of possible future selves" ( identity play), as opposed to utilizing a variety of strategies and behaviors to tailor, adapt or otherwise to change their identities in order to display role appropriate characteristics and to reach a stage of internal identity coherence (identity work).

The work of Markus and Nurius on the future orintated concept of 'possible selves', developed within a context of social cognitive studies of the self-concept and has been of significant importance to researchers and practitioners across disciplines.

According to Markus and Nurius [14, p.954] in their seminal paper, possible selves, a future selfstate rather than a current one, represents the ideas which an individual has regarding what they could become (hoped for self), what they would like to become (ideal self) and what they are afraid of becoming (feared self). Information derived from past experiences also plays a significant role in this regard as well as an imagined future dimension as not all cognitions are anchored in social reality.

Of particular relevance in regard to the concept of "possible selves" is the relationship between the selfconcept, motivation and social cognition (social and cultural based meaning). In other words, possible sleves give a direct link between motivation and our social and cultural understanding of the world around us using a social cognitive model of the self as a mediating link.

Indeed, Markus and Nurius [14, p.957] provide a broad outline of the scope of possible selves, that is, multiple future orientated selves - the successful self, the feared self, the athletic self - but do not provide a finite taxonomy, in contrast to the work of Higgins [7] and [8] .

Higgins et al [7, p. 320] proposed a taxonomy of three self domains consisted of the actual self, ideal self, and ought self. The actual self consists of representations of the attributes, which an individual (himself/herself or another) believes he/she actually possesses. The ideal self consists of the representation of the attributes (hopes, aspirations or

wishes for an individual), which someone (an individual or another) would like himself/herself ideally to possess. The ought self is a representation of the attributes of that an individual (himself/herself or another) believes he/she should or ought to possess (sense of duty, obligations or responsibilities).

In keeping with the motivational self-systems and self-discrepancy theory in particular and adapting the work of Kubanyiova [12] on multiple language teacher selves, the possible teacher self might consist of the ideal teacher self, which constitutes identity goals and aspirations of teachers. It furthermore might involve the self which teachers would ideally like to attain.

In addition, it is assumed that, irrespective of what the content of this ideal self is, teachers will be motivated to expend effort to reduce a discrepancy between their actual and ideal teaching selves.

The ought-to Teacher Self might then refer to the "teachers cognitive representations of their 
responsibilities and obligations with regard to their work" [12,p. 316]. This may involve, what Dinham and Scott [4] refer to as micro- and macrosociocontextual variables, for example, expectations of colleagues, students or normative pressures of the higher education institute, government policy concerning education or public perception of education provision.

As opposed to the previous type of self, the teachers' activity geared towards reducing the actual versus ought-to self-discrepancy, according to Kubanyiova [12] is motivated by extrinsic incentives and the primary source of this motivation is believed to be the teacher's vision of negative consequences.

Kubanyioca [12] also advocates that a teachers vision of negative consequences would represent a third type of possible self, namely, the feared self. This would refer to a possible self the teacher may become, if either the ideals or teacher's perceived obligations and responsibilities are not lived up to.

Self-regulatory efforts towards reducing the actualversus-possible selves discrepancy are likely to increase when teachers have 'balanced' possible selves. How this could be potentially achieved is discussed further in section 6 .

\section{The temporal dimension of teacher motivation - towards promoting "balanced" possible selves via advancement contingency paths}

Teacher motivation is not just about the intrinsic motivation to teach. It is "about the motivation to be a teacher as a lifelong career" [5, p.162] and it is this career perspective that highlights a temporal dimension of teaching faculty motivation. Dörnyei [5, p. 163], in particular, refers the reader to the work of Raynor [16] and [17] and Pennington [15] on long-term achievement strivings, and stresses its relevance to the understanding of teacher motivation. Raynor [17, p.371], also commented on in Dörnyei, [5, p.163] defines careers as "interrelated sets of skill-demanding activities that are engaged in by individuals over time".

In order to have a better understanding of the motivational foundation of the pursuit of a career, Raynor [16] introduced the concept of a contingent path, referring to "a series of tasks where successful achievement is necessary to be guaranteed the opportunity to perform the next task, that is, to continue in the path". Raynor [16] continues by stating that this implies that, in a contingent path, "immediate success is known to guarantee the opportunity for subsequent career striving, and immediate failure is known to guarantee future career failure though loss of opportunity to continue that career path" [36, p.372], cited in Dörnyei [5, p.163]
On closer examination of the work of Raynor [16,p. 36], Dörnyei [5] emphasizes that from a pathcontingency perspective, external motives such as money, power, prestige, security, public acclaim, and approval of family and friends are just as important determinants of career motivation as intrinsic ones (interest in the profession, acquisition of special competence, successful task completion).

Dörnyei [5] further emphasizes that an important element of contingent path theory is the recognition that many careers are so structured that their hierarchy of advancement "has a clearly defined final or upper plateau", that is "a closed contingent path", while others are seen as essentially "open-ended".

In closed paths, achievement motivation decreases with advancement, whereas open paths "sustain persistence and prolonged effect because additional possibilities for continued career-related striving become apparent as the individual moves along the career path" [5, p.165].

The possibility that advancement contingency paths can be established even in the field of education is also represented in Pennington's [15, p.209-210], sample career ladder. Some steps in this structure include the increased variety of courses taught, contribution to curriculum development, monitoring role of new faculty, being in charge of developing new courses/programmes, making conference presentations and/or preparing professional publications, serving as teaching consultant within and outside the institution, conducting teachertraining workshops and developing materials for use in the home institution and elsewhere.

\section{Self-authorisation, self-reflection and critical engagement in multiple spaces}

Very much associated with the temporal dimension of teaching faculty motivation, advancement contingency paths, the impact of micro- and macro-contextual variables as well as the notion of possible and ideal selves is the notion of self-authorisation, self-reflection and critical engagement in multiple spaces (both smooth and striated spaces of learning).

"Navigating the complexities of twenty-first century life requires self-authorship, or the development of an internal voice to guide one's beliefs, identity and relationships", Baxtor Magolda [2] postulates.

The concept of self-authorship emerged from the constructivist-developmental research tradition. Constructivism refers to humans tendency to construct meaning by interpreting their experiences. Developmentalism suggests that these constructions evolve over time through periods of stability and transition to become more complex [2]. It could be argued that in the context of teaching faculty in higher education, competing demands and challenges 
we face today erodes our capacity to self-reflect and to develop and exercise an internal voice to coordinate external influence. Developing an internal voice to guide one's experiences "enables one to recognize and engage in opportunities for growth as well as to develop and the kinds of partnerships that support it" [2, p. 99].

Savin- Baden [19] refers to the idea that there are "diverse forms of spaces within the life and life world of the academic", where opportunities exist to reflect and analyse one's learning and experiences" $[19$, p.8].

Savin-Baden [19] has provided numerous examples of the types of diverse learning spaces in which learners may reside. Some examples include work, non-work, occupational networks; family, leisure, social networks and engagements as well as manifold channels of news, information and communication and physical and global mobility (actual and virtual). Further examples might include bounded learning spaces (days away in which to think and reflect as a group); formal learning spaces (courses and conferences, social learning spaces (dialogue and debate in informal settings). As well as this, spaces could also be perceived as silent learning spaces (away from noise that erodes creativity, innovation and space to think), writing spaces (places not only to write but to consider one's stances and ideas) and dialogic spaces (critical conversations where the relationship between the oral and the written can be explored).

In regard to higher education, Savin-Baden [19] places a strong argument, which also was of particular importance to us, for the need for more recognition of the creation and maintenance of smooth spaces in striated learning environments and the possible interplay of both types of learning spaces as well her emphasis on the notion of "spatial ecology".

Savin-Baden distinguishes between smooth and striated spaces of learning. She defines striated learning spaces as spaces "characterised by a strong sense of organisation and boundedness" [19, p.154].

Such spaces could be deemed to be "spaces of arrival", for example, course attendance on campus or defined learning places such as lecture theatres and classrooms. Smooth spaces, by contrast, are deemed to be "open, flexible and contested spaces in which both learning and learners are always on the move" [19, p.153], that is, "spaces of becoming". In such spaces, there is also a sense of displacement of notions of time and place so that the learning space is not defined but is defined by the creator of the space. In other words, in such spaces learners are encouraged to contest knowledge and ideas preoffered by the lecturer and in so doing create their own stance (one's attitudes, beliefs or disposition towards a particular context, person or experience [19, p.154].
She also refers to, defines and emphasises the importance of the notion of "spatial ecology" as the "creation of balance between and across spaces in higher education, so that account is not taken of merely knowledge, content, conceptions and acquisition, but also of ontology, of values and beliefs, uncertainty and complexity" [19, p.154].

Savin-Baden [19] provides a number of creative learning spaces in which teaching faculty may inhibit to reflect and construct new meaning (potential contingencies paths). Such spaces might include:

- bounded learning spaces (days away in which to think and reflect as a group);

- formal learning spaces (courses and conferences);

- social learning spaces (dialogue and debate in informal settings);

- $\quad$ silent learning spaces (away from noise that erodes creativity, innovation and space to think);

- writing space (places not only to write but to consider one's stances and ideas);

- dialogic spaces (critical conversations where the relationship between the oral and the written can be explored);

- reflective learning spaces (which reach beyond contemplation and reconsidering past thought, they are spaces of meaningmaking and consciousness-raising);

- digital learning spaces (where explorations occur about new types of visuality, literacy, pedagogy, representations of knowledge, communication and embodiment).

Indeed it could be advocated that the wider the array of contexts, (spaces for learning- past, present and future), the more capable and willing teaching faculty will be to generate possible and ideal selves. Furthermore there needs to be more emphasis placed on and recognition of smooth (open, contestable) spaces of learning as opposed to the traditional striated spaces of learning (strong sense of organisation and boundedness) prevalent in higher education systems.

It could also be argued that the concept of selfauthorship as well as self-reflection and critical engagement in multiple spaces is very much link to the notions of complementary notions of identity work and identity play. Despite a growing interest in identity processes pertaining to teaching faculty in Higher Education Institutions, researchers still know very little about how work identities actually change in line with changes or transitions - skills focus, method focus, reflection focus, institutional focus, disciplinary focus. In light of this Ibarra and Petriglieri [10] present a strong argument that spaces of authoring in organizations need to incorporate the 
notion of not only identity work and but should also focus on an alternative but complementary notion of identity play.

The notion of Identity work is defined as "people's engagement in forming, repairing, maintaining and strengthening and revising identities" [10, p.10]. The notion of identity play is perceived as "playful processes necessary for creating new identities" and furthermore as "people's engagement in provisional but active trial of possible future selves" $[10, \mathrm{p} .10]$. The notion "identity play" furthermore embraces the need to escape performing within the boundaries of an existing professional identity. The individual explores and reflects on numerous possible selves, each corresponding to equally numerous personal and professional possibilities [10, p.15-p. 17]. In addition, as the notion of identity play is linked to the concept of possible selves, constraints of coherence and continuity are loosened to report aspects of themselves which are independent rather than connected [10, p.20].

It could be argued that further research is needed to explore the temporal and spatial features that encourage identity play in order to gaining a clearer understanding of conditions under which settings may or may not function as identity "playspaces".

\section{Conclusion}

There is an onus on higher education institutions to contribute to the enhancement of teaching faculty motivation. There are a number of forms of possible response to this issue. Such possible forms may include the encouragement, facilitation and accrediation of teaching faculty in gaining worthwhile experiences through continuous professional development. It also entails offering opportunities for systematic reflection, both individual and collective reflection, on learning and teaching experiences such that the learning and personal value of those experiences are enhanced. Furthermore, shaping the higher education institute's own courses to promote the scholarship of teaching and learning may provide the best chance of maximising and applying the learning potential of the various experiences of teaching faculty in both smooth and striated learning environments.

\section{References}

[1] Altbach, P. (2000). The deterioration of the academic estate: International patterns of academic work. In P. Altbach (Ed.), The changing academic workplace: Comparative Perspectives (pp. 1-33). Boston: Boston College Center for International Higher Education.

[2] Baxtor Magolda, M. $(2011,75)$ Authroring your life: A lifewide learning perspective. In N. J. Jackson (eds),
Learning for a complex world: A Lifewide Concept of Learning, Education and Personal Development, Bloomington, USA, AuthorHouse, pp.76-99.

[3] Dahl, D.W. \& Smimou, K. (2011) "Does motivation matter?: On the relationship between perceived quality of teaching and students' motivational orientations". Managerial Finance, 37(7), 582 - 609.

[4] Dinham, S. \& Scott, C. (2000). Moving Into The Third, Outer Domain Of Teacher Satisfaction , Journal of Educational Administration, 38 (3), Vol. 38 pp.379-96.

[5] Dörnyei, Z. (2001) Teaching and Researching Motivation. Applied Linguistics in Action Series. Harlow Essex, Pearson Education.

[6] Dörnyei Z. (2009) The L2 motivational self-system. In Zoltán Dörnyei and Ema Ushioda (ed.) Motivation, Language Identity and the L2 Self (pp. 9-39 ). Bristol: Multilingual Matters.

[7] Higgins, E. T., Klein, R. and Strauman, T. (1985). Selfconcept discrepancy theory: A psychological model for distinguishing among different aspects of depression and anxiety. Social Cognition, 3, 51-76.

[8] Higgins, E. T. (1987) Self-Discrepancy: A theory relation Self and Affect. Psychological Review Vol 94, No.3, 319-340.

[9] Hongping, Z. (2006) Motivating Teaching Staff in times of change in Chinese Universities. Canadian Social Science Vol.2, 37-45.

[10] Ibarra,H. and Petriglieri, Jennifer L., (2010) "Identity work and play", Journal of Organizational Change Management, Vol. 23 Iss: 1, pp.10 - 25.

[11] Kezar, A. and Sam, C. ,2010. Understanding the New Majority of Non-Tenure-Track Faculty in Higher Education: Demographics, Experiences, and Plans of Action: ASHE Higher Education Report, Volume 36, Number 4.

[12] Kubanyiona, M. Possible selves in language teacher development. In Dörnyei, Z., \& Ushioda, E. (Eds.) (2009). Motivation, language identity and the L2 self. Bristol, UK: Multilingual Matters, Ch.16.

[12] MacIntyre, Peter, D., Mackinnon, S.P. and Clement, R. (2009) The Baby, the Bath Water and the Future of Language Learning Motivation Research. In Zoltán Dörnyei and Ema Ushioda (ed.) Motivation, Language Identity and the L2 Self (pp. 9-39 ). Bristol: Multilingual Matters.

[13] Mannix, V. (2008) Motivation, the Language Learner and Teacher. PhD Thesis. University College, Cork, 2008. [14] Markus, H.R. and Nurius, P. (1986) Possible selves. American Psychologist, 41, 954-969.

[15] Pennington, M. C. (1995) Work satisfaction, motivation and commitment in teaching English as a second language. ERIC Document Reproduction Service No. ED 404850. 
[16] Raynor, J. O. (1974a) Future orientation in the study of achievement motivation. In: J. W. Atkinson, and J. O. Raynor (eds) Motivation and achievement. Washington, DC, Winston and Sons. pp. 121-154.

[17] Raynor, J. O. (1974b) Motivation and career striving. In: J. W. Atkinson and J. O. Raynor (eds) Motivation and achievement. Washington DC, Winston and Sons. pp. 369387.

[18] Riches, C. (1994) 'Motivation', in Bush, T.\&WestBurnham, J. (Eds.). The principles of Educational Management. Harlow: Longman.

[19] Savin-Baden, M. (2008). Learning Spaces: Creating Opportunities for Knowledge creation in academic life. Open University Press, McGraw Hill: England. 